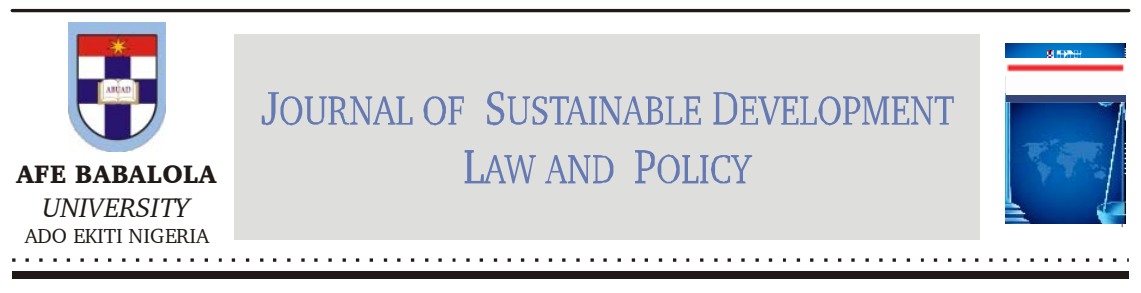

\title{
CLIMATE CHANGE ADAPTATION AND ITS IMPLEMENTATION AT NATIONAL AND INTERNATIONAL LEVELS
}

\author{
Olubunmi Ayodele Afinowi*
}

\begin{abstract}
Climate change adaptation is the second arm of climate change action and seeks to ensure that all countries tackle the impacts of climate change by addressing both social and geographical vulnerabilities. The article discusses adaptation and its application at national and international levels. It also examines adaptation to climate change as a developmental challenge and how the principles of sustainable development can aid climate change action. The article analyses relevant aspects of national and international instruments relating to climate change adaptation and spotlights the commitment of Nigeria and South Africa to climate change adaptation. The article finds that integrating sustainable development into governance helps adaptation and increases resilience against the impacts of climate change. The article also emphasizes the necessity of good governance, particularly protection of human rights, climate finance and effective land use governance, to ensure climate change adaptation. The article argues that climate change adaptation should be viewed more as a developmental, rather than an environmental, challenge. It further asserts that coordinated action, especially in relation to land use governance and sustainable development is required to ensure sustainable climate action. This is particularly so given that citizens of many developing countries, including Nigeria and
\end{abstract}

* $\mathrm{PhD}$ (University of Cape Town, South Africa), Lecturer, Faculty of Law, University of Lagos. 
South Africa, depend on land and its resources for social and economic development.

Keywords: Adaptation; Climate Finance; Good Governance; Nigeria; South Africa.

DOI: https://dx.doi.org/10.4314/jsdlp.v11i2.7

\section{INTRODUCTION}

Adaptation is an aspect of the response to climate change at national and international levels. Unlike mitigation, which entails reducing sources of environmental pollution, adaptation is less of an environmental problem ${ }^{1}$ and more of a developmental problem. ${ }^{2}$ As will be seen in this article, the impacts of climate change on natural and human systems indicate that adaptation should be perceived as a developmental challenge to which the principles of sustainable development should be applied. ${ }^{3}$

Though human systems and communities have a natural tendency to adapt to changes that occur in their physical environment and have been doing so for centuries, ${ }^{4}$ the availability of scientific knowledge on the likely extent of the impacts of climate change makes it possible for actions to be taken in anticipation of climate impacts within human systems. Such actions include incorporating adaptive measures into

1 G. Zeirvogel, "Climate change impacts and adaptation in South Africa" (2014) WIREs Clim Change 605, 606.

2 L. Kotze and others, "Climate change law and governance in South Africa Setting the Scene" in T. L. Humby and others (eds), Climate Change: Law and Governance in South Africa (Juta, Cape Town 2016) 1-6.

3 To this end, the United Nations has come up with Agenda 2030 in a bid to ensure a global and uniform integration of the principles of sustainable development into governance. Particularly, Sustainable Development Goal 13 (SDG 13) speaks to the necessity of climate action.

4 Lim, Bo and E. Spanger-Siegfried (eds), Adaptation Policy Frameworks for Climate Change: Developing Strategies, Policies and Measures (Cambridge University Press, Cambridge 2004) 1. G. Ziervogel and S. Parnell "Tackling barriers to climate change adaptation in South African coastal cities" in B. C. Glavovic and G. P. Smith (eds) Adapting to Climate Change: Lessons from Natural Hazards Planning (Springer Science and Business, New York 2014), 67 \& 70. 
government policies, ${ }^{5}$ especially in line with Sustainable Development Goal 13 (SDG 13) which requires countries to take action to combat climate change and its impacts. ${ }^{6}$ The tendency of climate change impacts to be so far-reaching as to affect every aspect of human endeavour and interactions further makes it necessary to bolster adaptive capacity ${ }^{7}$ at all levels of government, as well as among private sector stakeholders, groups and individuals. ${ }^{8}$ The importance of adaptation to climate change is further underscored because the impacts are likely to continue over an extended period. Hence the need to formulate short-, mid- and longterm adaptation frameworks. ${ }^{9}$ It is in light of this that the article focuses on adaptation and its effective implementation.

The article is divided into five sections. After this introduction, section 2 discusses the nature and scope of adaptation. Section 3 focuses on climate action at the national and subnational level and how various factors such as law, sustainable development and land governance engender or promote adaptation to climate change. Section 4 discusses how adaption principles can be incorporated into government planning and decision making processes. Section 5 is the concluding section.

\section{ADAPTATION}

Adaptation connotes and is used to mean different things in various disciplines. ${ }^{10}$ In the context of human adjustment to external stimuli, Charles Darwin applied the concept contextually by acknowledging the ability of organisms to modify themselves to suit their changing

5 Ibid.

6 UN, Transforming our world: The 2030 Agenda for Sustainable Development, UNGA/A/RES/70/1, 25.

7 N. Brooks, in his work, "Vulnerability, risk and adaptation: A conceptual framework", Tyndall Centre for Climate Change Research Working Paper 38 at page 8 describes "adaptive capacity" as the ability or capacity of a system to modify or change its characteristics or behaviour so as to cope better with existing or anticipated external stresses.

8 L. Kotze and others (note 3) 1-7.

9 C. B. Field and others (eds), Climate Change 2014: Impacts, Adaptation, and Vulnerability Part A: Global and Sectoral Aspects. Contribution of Working Group II to the Fifth Assessment Report of the Intergovernmental Panel on Climate Change (IPCC 2014AR5), (Cambridge University Press, Cambridge and New York 2014) 837.

10 ELF Schipper "Climate change adaptation and development: Exploring the linkages" (July 2007) 107 Tyndall Centre Working Paper, 4-5. 
environment. ${ }^{11}$ John Dewey built on Darwin's theory by defining the term as meaning how individuals and groups gather knowledge about their environments in order to respond adequately to the environment and attain their own goals. Dewey's perception of adaptation in this context entailed acquiring knowledge of the environment, ability to respond effectively to the environment and the recurring changes happening within it, as well as modify the environment, as the need arises, to aid continued existence. ${ }^{12}$

Adaptation in whatever form involves reducing the adverse effects of a state of affairs or condition on human societies and sources of livelihood. ${ }^{13}$ Following Charles Darwin's theory, the process of adaptation in most organisms and natural systems is not always a deliberate effort, and environmental adaptation has been a continuous semi-deliberate process for human systems for centuries. ${ }^{14}$ The reality is thus that in all human systems and societies, adaptation would include any passive, reactive, or anticipatory modification of social, economic and even cultural lifestyles. ${ }^{15}$ This form of continuous semi-deliberate process of adaptation is already extending to climate change and its impacts. Climate change impacts, however, raise new issues of vulnerabilities, not only regarding the natural or biophysical environment but social vulnerabilities which put many human systems at great risks and require streamlined and coordinated efforts at adaptation. ${ }^{16}$

\subsection{Climate Change Adaptation}

Adaptation to climate change transcends minor adjustments to changing weather and entails numerous transboundary and global impacts which

11 Ibid p. 4.

121 Adger and others also note that it is inherent in all organisms to adapt to changes within their environment by acquiring knowledge of their environment and using such knowledge or information to respond to the changes in the environment. See WN Adger, I Lorenzoni and KL O'Brien, "Adaptation now" in WN Adger and others (eds) Adapting to Climate Change: Thresholds, Values, Governance, (Cambridge University Press, Cambridge 2009), 1.

13 G. J. Nagy and others, "Adaptive capacity for responding to climate variability and change in estuarine fisheries of the Rio" de la Plata (2006) 36 AIACC Working Paper, 3.

14 H. Bulkeley and R. Tuts "Understanding urban vulnerability, adaptation and resilience in the context of climate change" (18)6 Local Environment 646, 654-5.

15 IPCC AR5 Part A (note 9), 836.

16 H. Bulkeley and R Tuts (note 14). 
are drastic and intense. ${ }^{17}$ Critical aspects of adaptation are reduction of vulnerabilities, building of resilience and disaster risk response and management. It also includes actions aimed at curtailing damage, actions taken to recover from the damage done and actions taken when recovery is slow or impossible. ${ }^{18}$

Adaptation to climate change entails transforming physical, environmental and socio-economic conditions so that minimal harm is experienced, while harnessing the associated benefits. This entails categorizing geographical areas based on their resilience or capacities to adapt, ${ }^{19}$ and identifying and reducing sensitivities to climate change by attaining a degree of preparedness through the improvement of socioeconomic conditions. ${ }^{20}$ While the capacity to adapt or improved socioeconomic conditions do not guarantee preparedness to face the impacts of climate change, these factors reduce social vulnerabilities ${ }^{21}$ to climate change.

In relation to climate change, adaptation was first defined by the intergovernmental panel on climate change (IPCC) in 2001 as "[a]djustments in natural or human systems to a new or changing environment ... in response to actual or expected climatic stimuli or their effects, which moderates harm or exploits beneficial opportunities". ${ }^{2}$

Adaptation is defined in the Fifth Assessment Report of the Intergovernmental Panel on Climate Change (IPCC AR5) as the process of adjustments to actual or expected climate and its effects. Specifically, in human systems, adaptation seeks to moderate harm or to exploit

17 W. N. Adger and others (eds), Adapting to Climate Change: Thresholds, Values, Governance, (note 12), 1.

18 Ibid, also H. Bulkeley and R. Tuts (note 12), 648-9.

19 J. B. Ruhl, "Climate change adaptation and the structural transformation of environmental law", 40 (2010) Environmental Law 363,385.

20 A. Kaswan, "Climate change adaptation and land use: Exploring the federal role", (2013) 47 Marshall Law Review, 509, 513.

21 Social Vulnerability, according to the IPCC AR5 refers to ways in which individuals, groups and communities are vulnerable to climate change impacts. Social vulnerability is based on several enhancing factors or drivers including gender, age, health, social status, and ethnicity of individuals and groups, and the capacity building institutions in place locally, nationally, regionally, and internationally, see IPCC AR5 Part A (note 7), 836-40.

22 J. J. McCarthy and others (eds), Climate change 2001: impacts, adaptation, and vulnerability: contribution of Working Group II to the third assessment report of the Intergovernmental Panel on Climate Change (IPCC AR3), (Cambridge University Press, Cambridge 2001), 90-1. 
beneficial opportunities. In relation to natural systems, adaptation by human intervention seeks to facilitate some adjustments to the climate and its effects. ${ }^{23}$

Adaptation to climate change, as identified by the IPCC, occurs in different ways and can be categorized based on various factors, including timing, scope, purposefulness and the adapting agent. ${ }^{24}$ Based on these factors, adaptation could be anticipatory/proactive or reactive, local or regional, short- or long-term, autonomous or planned, as well as individual or collective/government action. ${ }^{25}$

The IPCC in AR5 further highlights that planned adaptation in human systems could be incremental or transformational. ${ }^{26}$ Incremental adaptation is the maintenance of the integrity of human systems, such as institutional, economic, technological and social systems, to be able to withstand the impacts of climate change. ${ }^{27}$ Transformational adaptation, on the other hand, is aimed at changing fundamental aspects of human systems given the impacts of climate change. ${ }^{28}$ Such changes could relate to migration, lifestyle or the forfeiture of established ways of doing things for more adaptable methods. While the incremental form of adaptation entails a gradual integration of climate change adaptation considerations into governance, transformational adaptation is more radical and requires fundamental changes in the governance structure. ${ }^{29}$

The AR5 discusses another form of adaptation, that is, autonomous adaptation, which refers to a reactionary form of adaptation, as the measures taken are not a consequence of planned or conscious efforts to tackle climate change and its effects. ${ }^{30}$ The passive semi-deliberate adaptation process is not targeted at addressing climate change or its impacts on the society but it is important in building adaptive capacity

23 V. R. Barros and others (eds) Climate Change 2014: Impacts, Adaptation, and Vulnerability Part B: Regional Aspects Contribution of Working Group II to the Fifth Assessment Report of the Intergovernmental Panel on Climate Change (2014) (IPCC AR5 2014), (Cambridge University Press, Cambridge 2014), 1758.

24 IPCC AR3 (note 22), 88.

25 Ibid., 88-9.

26 This view is also supported by Bulkeley in H. Bulkeley and R. Tuts (note 14), 654-5.

27 AR5 2014 Part B (note 23), 1758; N Brooks and others, "Tracking adaptation and measuring development", (2011) IIED Climate Change Working Paper Development, 12.

28 Ibid.

29 H. Bulkeley and R. Tuts (note 14), 654-55.

30 IPCC AR5 Part B (note 23), 1759. 
among the bio-components of the environment, including individuals within the society. ${ }^{31}$

\subsection{Adaptation Delays}

Adaptation is often relegated to the background in matters of development. ${ }^{32}$ This is because it is often not based on facts or premises, but on scientific estimations and projections which have no element of uncertainty and variability. ${ }^{33}$

The United Nations Framework Convention on Climate Change (UNFCCC) seems to have foreseen such governance dilemma in addressing climate change impacts. Hence it states clearly that the absence or insufficiency of concrete scientific evidence should not be a reason not to take action where there is the likelihood of grievous and irreversible damage being done. ${ }^{34}$ Sussman ${ }^{35}$ and Flatt ${ }^{36}$ hold the view that rather than most developing countries delaying adaptation due to insufficient scientific evidence, some adaptation should be commenced based on available information and such measures should be improved upon or revised as more scientific knowledge becomes available.

Furthermore, some impacts of climate change may aggravate preexisting natural or social vulnerabilities in developing countries leading to more significant risks and hazards; in such cases, the argument for gradual societal adaptation becomes nullified. In the same way, the social and economic costs of unpreparedness are very likely to outweigh that of anticipatory measures towards adaptation. According to Craig, rather

31 IPCC AR5 Part A (note 9), 838.

32 O. Mertz, "Adapting to Climate Change in developing countries" (2009) 43(5) Environmental Management, 743,744; R. J. Klein, ELF Schipper, S. Dessai, "Integrating mitigation and adaptation into climate and development policy: three research questions", (2005) 8(6) Environmental Science \& Policy, 579, 586; E. Sussman and others, "Climate change Adaptation: Fostering progress through law and regulations", (2010) 18 New York University Law School Environmental Law Journal 55, 56; H. Bulkeley, "Cities and the governing of climate change", (2010) 35 Annu. Rev. Environ. Resour. 229, 244; T. E. Downing and others, "Adaptation to climate change in Africa", (1997) 2(1) Mitigation and adaptation strategies for global change, 19, 20-1.

33 E. Sussman and others ibid at p 57.

34 United Nations Framework Convention on Climate Change, Art 3 principle 3.

35 E. Sussman, (note 32), 61.

36 V. B. Flatt, "Adapting laws for a changing world: A systemic approach to climate change", (2012) 64 Fla.L.Rev. 269, 283. 
than delay action, climate change should be addressed with principled flexibility. ${ }^{37}$

Adaptation to projected climate change impacts is seen by most governments as a capital-intensive programme. The UNFCCC provides guidelines for adapting to the impacts of climate change, including funds transfer; and subsequent protocols to the Convention have set up a trust fund. ${ }^{38}$ This is partly based on the principle of international cooperation on technology and funds transfer as well as international environmental law principles, that is, the polluter-pays and trans-boundary pollution ${ }^{39}$ principles. However, there is the general problem of how to generate and access funds. There also seems to be a general scepticism to fund adaptation in developing countries because the processes of adaptation to climate change are economic and developmental, and the impacts are made worse by already existing deficiencies within many developing countries. It is hard, therefore, to establish the additionality of climate change adaptation projects.

\subsection{Proactiveness and Directness in Adaptation}

Besides monetary and socio-economic costs, there could also be political and legal implications to adaptation. For instance, the government may be unable to adequately respond to adverse effects, giving rise to issues of infringement of human rights, the breach of public trust, and failure to carry out governmental and constitutional obligations. ${ }^{40}$

In line with the above, the government has certain obligations, both constitutional and those contained in several international treaties, ${ }^{41}$ to

37 R. K. Craig, "Stationarity is dead - Long live transformation: Five principles for climate change adaptation law", (2010) 34(1) Harvard Environmental Law Review 9, 17, also N. H. Stern, The economics of climate change: Stern Review, (Cambridge University Press, New York 2007), 436.

38 Art 11 of the Kyoto Protocol to the United Nations Framework Convention on Climate Change http://unfccc.int/resource/docs/convkp/kpeng.pdf (accessed 31/03/2020). Also articles 10(b)(i)(c) (d) and 12(7) of the Protocol make reference to the transfer and establishment of funds to help developing nations meet the challenges of adaptation; also <https://www.adaptation-fund.org > and <http://unfccc.int/kyoto_protocol/items/2830.php>; J Paavola and WN Adger, "Justice and adaptation to climate change", Tyndall Centre Working Pape $r$ 23, 11-2, also The Stern Review (note 37), 554-5 and 557.

39 UNFCCC, Art 3 contains these and other principles recognized by the UNFCCC as being necessary in addressing the challenge of climate change.

40 These and other issues make climate change law and governance imperative.

41 The Constitutions of South Africa and Nigeria as well as the African Charter and the UN Charter recognize the right of citizens to live in a safe environment. 
improve, safeguard and protect lives and property within their jurisdictions. Adaptation - the need to safeguard the environment and society against the adverse effects of climate change - gives rise to a legal, binding obligation on the part of the government which requires direct and deliberate efforts to protect the public interest rather than passive or reactionary efforts. ${ }^{42}$

\subsection{Adaptation as Championed at the International Level}

The UNFCCC provides that State parties must minimize causes of climate change and take steps to reduce its adverse effects. It also encourages States to adapt cost-effectively, considering individual socioeconomic capacities. In other words, there need not be a universal template for adaptation, but each State is to adapt depending on its economic and social capacity. ${ }^{43}$ Given the transboundary nature of climate change and its effects, it also calls for regional or bilateral and multilateral cooperation in addressing climate change and its impacts. ${ }^{44}$ The Convention also enjoins State parties to take measures to mainstream adaptation into existing government policies across all sectors. ${ }^{45}$

42 The African Commission on Human and Peoples Rights, in recognizing the need to take proactive steps to safeguard the rights of people in relation to climate change and its impacts, has passed three Resolutions: Resolution ACHPR/Res. 153(XLVI)09: Resolution on Climate Change and Human Rights and the need to study its impacts in Africa adopted at its 46th session in 2009; ACHPR/Res. 271 (2016): Resolution on Climate Change in Africa adopted at its 55th ordinary session in 2014 and ACHPR/Res. 342(LVIII)2016: Resolution on Climate Change and Human Rights in Africa.

43 There are various factors that militate against the adaptation ability or capacity of various nations, especially among developing countries. A major factor is the availability of funds. Most of these countries are further aggravated by climate change as they lack the monetary capacity to carry out developmental projects. In view of this fact, the Stern Review highlights the need for international collaboration not just in mitigation, but also in adaptation. It notes that: "...governments... will require support from the international community. The poorest countries are the most vulnerable to the impacts of climate change and are particularly short of the resources required to manage a changing climate. The ethical foundations for this support... are (i) that common humanity points to support for the poorest members of the world community, and to efforts to build a more inclusive society, (ii) the historical responsibility of industrialized countries for the bulk of GHGs concentrations, and (iii) a common interest in avoiding the instabilities that could arise from the transfer of the dislocation of climate change." Stern Review (note 37), 554-5.

44 UNFCCC, Art 3(3) and Art 4(4).

45 Ibid., Art $4(1)(b)(e)$ and $(f)$. 
After the UNFCCC, there have been some protocols that have emphasized the adaptation agenda and the setting up of a special adaptation fund. ${ }^{46}$ The Paris Agreement came up with a global goal towards achieving adaptation, a goal aimed at building adaptive capacity, increasing resilience, reducing vulnerabilities and eventually contributing to sustainable development in a bid to protect people, societies, sources of livelihoods and preserve the natural environment. ${ }^{47}$

The United Nations Environment Programme (UNEP) has done notable work on adaptation by harnesses knowledge and resources to aid adaptation at regional, national and local levels and making these resources available to countries to aid their adaptation process. The Programme also helps countries strengthen "... institutional and policy frameworks for adaptation ... [through] national development planning and legislative processes." ${ }^{8}$ UNEP also established a global adaptation network (GAN) and regional networks. Through these networks, it fosters multilateral interactions on adaptation to climate change in addition to supporting developing countries. Also, UNEP has a programme to support developing countries in actualizing their National Adaptation Plans, ${ }^{49}$ helping them to access funds from different sources to aid their adaptation process.

As mentioned earlier, another international effort towards adaptation to climate change is the 2030 Agenda for Sustainable Development. ${ }^{50}$ In line with the UNFCCC, the parties to this framework for sustainable development set out some goals towards achieving adaptation to climate

46 Notable among these are the Cancun Agreements Decision 1/CP.16, available at <http://unfccc.int/adaptation/items/5852.php $>$ and the Bali Action Plan Decision 1/CP.13 available at <http://unfccc.int/resource/docs/2007/cop13/ eng/06a01.pdf $>$ accessed 1/03/2020.

47 Arts 7 and 8 of the Paris Agreement FCCC/CP/2015/10/Add.1 Dec. 1/CP.21 available at <http://unfccc.int/resource/docs/2015/cop21/eng/10a01.pdf > accessed 1/03/2020.

48 Climate change adaptation: Knowledge support and Policy Integration < http:/ /www.unep.org/climatechange/adaptation/KnowledgeandPolicy/tabid/ 29577/Default.aspx> accessed 01/03/2020.

49 The National Adaptation Plan - Global Support Programme (NAP-GSP) for non-Least Developed Countries (non-LDCs) commenced in July 2015, it is funded by the Special Climate Change Fund of the Global Environment Facility see < http://www.undp-alm.org/projects/naps-ldcs/news-updates > accessed 01/03/2020.

50 Transforming our world: the 2030 Agenda for Sustainable Development, (note 6). The Agenda was adopted by world leaders at the what has been described as "an historic summit" in September 2015. 
change impacts. On adaptation and adaptive capacity, the Agenda seeks by 2030 to have achieved global resilience across sectors in all cities of the world. ${ }^{51}$ In addition to this, it advocates urgent action to tackle climate change and its impacts by helping to integrate climate change measures into countries' policies and planning. ${ }^{52}$ It also seeks to implement the raising of funds to promote climate change mitigation and adaptation as established under the UNFCCC. ${ }^{53}$

A controversial aspect of climate change governance at the international level is liability for loss and damage. It initially was suggested that developing countries, especially the small island countries, should be compensated for the effects of climate change for which developed countries were to be liable. ${ }^{54}$ The clamour for liability and compensation led to the Warsaw International Mechanism for Loss and Damage which was established pursuant to the Cancun Adaptation Framework. ${ }^{55}$ The Mechanism was enhancement of action, knowledge and dialogue on "comprehensive risk management" to address losses and damages associated with adverse effects of climate change. ${ }^{56}$ At the COP 21, there were negotiations to establish "loss and damage" liability and compensation as a third independent leg of climate change action, this move was kicked against by the developed nations as it purported to impose mandatory payments on developed countries for losses suffered by vulnerable states. ${ }^{57}$ And the Paris Agreement (PA), in seeking to resolve the issue took a middle ground which ensures the continued existence of "loss and damage". ${ }^{58}$ Rather than imposing liability for adverse effects of climate change though, the PA merely encourages states to cooperate to enhance action and provide support on loss and damage associated with effects of climate change. ${ }^{59}$

51 Goal 122030 Agenda (note 6).

52 Goal 13.2 2030 Agenda (note 6).

53 Goal 13.3 of the 2030 Agenda (note 6).

54 Climate Focus Briefing Note "Loss and damage in the Paris Agreement" December 2015, 2-3.

55 Decision 2/CP. 19/FCCC/CP/2013/10/Add.1 Report of the Parties on its nineteenth session.

56 FCCC/CP/2012/8/Add.1 Report of the Conference of Parties on its eighteenth session, Decision 3/CP.18, para 5.

57 Climate Focus (note 54), 3; RS Dimitrov, "The Paris Agreement on Climate Change; Behind closed doors", (2016) 16(3) Global Environmental Politics, 1 $11,4$.

58 Paris Agreement, Art 8, ( note 47).

59 Paris Agreement, Art 8 para 3 \&4 (note 47); See C. Okereke and P. Coventry, "Climate justice and the international regime: before, during and after Paris", 


\section{CLIMATE CHANGE ADAPTATION AND THE LAW}

Adaptation to climate change is regarded as a public good. Hence no one can ordinarily be excluded from enjoying or benefitting from it; it is a non-excludable good. ${ }^{60}$ Given this background, it requires the sanction of the law for several reasons.

First, a legal backing is necessary to ensure climate change adaptation retains its character of non-exclusion in all forms. To this end, it is essential to have clear and uniform adaptation objectives and framework backed by law and applicable across sectors. ${ }^{61}$ The legal framework for adaptation should actualize three main normative goals: reducing vulnerability, increasing resilience to climate change, and maintaining equity in the adaptation process. ${ }^{62}$ The first two goals are central themes to adaptation in general; the third speaks to rule of law and justice. Adaptation equity examines the adaptation process and seeks the most efficient and equitable way to engage the instrument of the law in such circumstances. ${ }^{63}$

Second, the fact that climate change impacts have far-reaching physical, social, economic and developmental effects calls for the intervention of the law to ensure climate justice. ${ }^{64}$ According to Adger, adaptation to climate change raises issues of justice, responsibility and obligations for the adaptation process. ${ }^{65}$ Adaptation should be viewed as a core governance issue which requires deliberate action by the people of an area, either through a collective will or by individual efforts. The law, in this regard, serves to ensure the effectiveness of government volition to carry out adaptation. It gives legal backing to any action taken on adaptation and allows for any player - whether government, private interviewee or individual - to be held answerable for actions or inactions

(2016) 7(6) Wiley Interdisciplinary Reviews: Climate Change, 834 -851; A. Savaresi, "The Paris Agreement: a new beginning?", (2016) 34(1) Journal of Energy and Natural Resources Law, 16 -26, 23.

60 G. Sosa-Nunez and E Atkins, Environment, Climate Change and International Relations available at www.E-IR.info accessed 31/10/2016,18-9; S. N. Seo, "A theory of adaptation to climate change as a global public good", (2010) USAEEIAEE WP, 8.

61 J. B. Ruhl and J. Salzman, "Climate change meets the law of the horse", (2013) 62(5) Duke Law Journal, 975,1019.

62 V. B. Flatt (note 36), 290-91.

63 Ibid.

64 E. Sussman and others (note 32), 60.

65 WN Adger, I. Lorenzoni and K. L. O’Brien, "Adaptation now" (note 12), 2. 
that jeopardize the adaptation process.

Third, the adaptation process raises legal issues connected to the environment and physical/spatial planning such as:

- The duty of the government to safeguard the environment and to provide the citizens with a clean and safe environment to live in;

- Compulsory acquisition or limitation of rights to private property to prevent development in certain areas because such land is not safe to inhabit;

- Relocation of inhabitants of unsafe areas;

- Payment of compensation for injury or damage that can be attributed to climate change;

- Tenure of land as it affects sectors such as agriculture and development;

- Adaptation obligations on private establishments and individuals and the liability for non-compliance with such directives;

- $\quad$ Obligation of government to provide basic infrastructure made more essential by climate change impacts, for instance, water, measures for disaster management and reduction;

- $\quad$ Planning and re-planning of areas likely to be affected by impacts such as floods, coastal erosion and drought.

Finally, law becomes essential in the adaptation process when the complex nature of the problem is considered. ${ }^{66}$ Many climate change impacts are drastic and, at times, irreversible. The laws and policies governing the pre-climate change era mostly become inadequate to address these issues properly. Such laws, especially in developing countries, will be insufficient motivation for the government to take deliberate action on climate change. ${ }^{67}$

The law and relevant regulations must maintain a level of flexibility 68 in addressing adaptation to climate change. The need for adaptation is global, but a significant characteristic of successful adaptation will be

66 Craig (note 37), 24-6, also IPCC AR5 Part A (note 9) and Stern Review (note 37) 56, 97 and 112.

67 Craig (note 37), 31.

68 E. Sussman and others (note 32), 60. The need for flexibility was also highlighted in the Stern Review, the Review points out that due to the relative inability to accurately predict climate change impacts (especially in developing 
the ability to address local impacts while still adhering to overarching global principles and social goals. In essence, adaptation reflects "local circumstances and needs" without being "subject to local veto or avoidance". ${ }^{69}$

\subsection{The Role of Land Use Governance in the Adaptation Process}

The UNFCCC and SDG 13 require nations to formulate measures to facilitate adaptation to climate change. ${ }^{70}$ The Convention specifically requires adaptation in coastal zone management, water resources, and the protection and rehabilitation of areas affected by floods and droughts. ${ }^{71}$ In this regard, physical planning and land use management are critical tools for working towards adaptation objectives of the UNFCCC..$^{72}$ Land use governance has always been amenable to changes within the society, such as industrialization, increased developmental and economic activities and land use changes. Moreover, land use governance legislation is designed to accommodate, anticipate and guide such changes. In relation to climate change adaptation, land use governance laws can be employed to reposition development and, thereby, reduce the sensitivity of the natural or human system to impacts, and increase the capacity to cope with impacts as or where they occur. ${ }^{73}$

Land use legislation are tools of social order and help to ensure a balance in social, economic and developmental activities as they relate to land use and the environment. ${ }^{74}$ Adaptation also seeks a balance of these activities in reducing climate change impacts. Thus, an adoption of the underlying principles of sustainable development in land use governance will help to ensure that social justice, equity, sustainability and resilience are considered in the process of climate change adaptation. ${ }^{75}$ Land Use governance, as a tool for promoting adaptation,

countries), the adaptation process should be flexible enough to be "able to respond to new information, and robust enough to be cost-effective across a range of possible future scenarios." Stern Review (note 37), 436.

69 Craig, (note 37), 17, also Stern Review (note 37).

70 UNFCCC, Art 4(1) (b); Transforming our World, (note 6).

71 UNFCCC, Art 4(1)(e).

72 C. Harris "Zoning" in E. Sussman op cit note 30 p 64.

73 A. Kaswan (note 20) 513.

74 C. Harris "Zoning" in E Sussman (note 30), 64 - 5.

75 B. C. Glavovic and G. P. Smith (note 4), 21. 
will also address developmental and environmental issues of public interest. ${ }^{76}$

Adaptation through land use governance and developmental activities also entails the protection of areas from the impacts of climate change through the provision of infrastructure. For instance, by constructing walls or embankments to control flood or prevent coastal erosion because of sea level rise. Such protection measures include the preservation of natural buffers that act as receptacles for floods or reduce the impact of climate change on human systems; this as well can be integrated into existing physical planning and coastal management agenda. ${ }^{77}$

Land use governance could also be aimed at accommodating or containing impacts within existing developed areas. This is achieved through re-zoning and building regulations that consider climate change impacts such as new setbacks, soft landscaping, greening infrastructure and other measures aimed at reducing impacts. Kaswan ${ }^{78}$ discusses retreat as a form of adaptation to climate change impacts. Like other forms of adaptation, retreat occurs on an individual basis or in a governmentcoordinated manner. People could vacate their land without government intervention, either temporarily or permanently as a result of flood, coastal erosion or even drought. Retreat could also be a coordinated government action through land use governance to restrict development in certain areas that are likely to experience grave dangers, ${ }^{79}$ or areas that have experienced some impacts and are not faring well post-impact, or areas susceptible to further risks. For instance, where ordinarily unhealthy or hazardous land use or activities are carried on in areas prone to climate change impacts, this should trigger adaptation through land use planning measures to avoid "collateral" injury or damage. A close example of the use of "retreat" through planning as a form of adaptation is seen in the new establishment of coastal management lines in the Western Cape. It is worthy of note here that the adaptation through "retreat" would be a justification of the exercise of government expropriation powers as provided for in sections 25(2) and 44 of the Constitutions of both South Africa and Nigeria. This power of expropriation could be evoked especially

76 B. C. Glavovic and G. P. Smith (note 4), 26.

77 A. Kaswan (note 20), 513.

78 A. Kaswan (note 20) 514-5. According to Kaswan, this is the most controversial method of adaptation as it entails individuals and communities giving up their land and settlements.

79 Ibid., 515. 
in the governance of coastal lands or other geographically vulnerable areas where continued human inhabitation could increase vulnerability or even put the lives of such inhabitants at risk.

A major challenge for land use governance in climate change adaptation would be the issue of migration within and into urban areas, people will move away from areas of high risks and vulnerability or other climate impacts. ${ }^{80}$ This form of migration would lead to increased pressures and escalation of urban challenges already being experienced. This and other challenges make it imperative for adaptation to be mainstreamed into physical or spatial planning processes of the state so that they can be considered holistically. It also iterates the need for focus not just on the environmental or developmental impacts of climate change, but also on the social and economic impacts regarding government policies and the environmental, social and economic rights of people or groups likely to be affected by climate change.

\section{INTEGRATING CLIMATE CHANGE ADAPTATION INTO GOVERNMENT ACTION}

The IPCC definition of adaptation includes policy formulations and governmental action directed at adaptation. ${ }^{81}$ For adaptation to climate change to be meaningful, it must involve a planned and systematic action by the government or private stakeholders. Such action should be based on findings and projections on the changes in the climate, the impacts of such changes and the need to either maintain a state of social, economic and developmental existence or to improve on the factors as an adaptation move. ${ }^{82}$ The disposition of the government to climate change adaptation is important, as public entities, institutions and the process of governance play a crucial role in engineering the adaptation process. ${ }^{83}$ The government is the custodian and expression of the public will and must make decisions and engage in activities that represent the interest of all members of the society, or at least the interest of the majority, as well as protect the

80 Ibid., 516.

81 Ibid.

82 IPCC AR5 Part A (note 9), 874.

83 T. J. Finan and DR Nelson "Decentralized planning and climate adaptation: Toward transparent governance”, in W. N. Adger, I. Lorenzoni and K. L. O’Brien (eds) Adapting to Climate Change: Thresholds, Values, Governance (note 12), 336. 
interest of particularly weak members of the society. To this end, the primary goals of the government regarding adaptation include protecting vulnerable groups and members of the society by reducing social vulnerability and exposure to risk. ${ }^{84}$ Government is also obliged to provide information and resources, protect existing infrastructure, and provide specific public goods to aid adaptation. Finally, government should lead the way in the adaptation campaign and translation of policies into action $^{85}$ and be followed by private institutions and individual members of the society. ${ }^{86}$

\subsection{Relevance of Sustainable Development to Adaptation}

The 2030 Agenda for sustainable development represents proposed collaboration towards the actualization of sustainable development across both developed, developing and least developed nations. To clearly identify areas where action is most needed, the Agenda highlights 17 goals in which Climate Action constitutes SDG 13. SDG 13 clearly aims at strengthening resilience and adaptive capacity, integrating climate change measures into national policies, and improving education, awareness and capacity on mitigation, adaptation and so on. ${ }^{87}$ It has been noted that although not itself a legal document, the Agenda 2030 strongly iterates legal obligations that nations have committed to in terms of climate change action. ${ }^{88}$

84 The question as to what should be the guiding philosophy of government action has been asked. Should government action be based on the principle of egalitarianism, which seeks to see the optimal good for a few members of the society? Juxtaposed to the adaptation scenario, would it be sufficient if adaptation policies or processes are directed towards the vulnerable members of the society alone in a bid to reduce their vulnerability? On the other hand, should the utilitarian principle which seeks the greatest good for the greatest number of people be adhered to? That is, the adaptation process will seek to achieve "maximum efficiency" for all members of the society, including the natural environment. The conclusion is that for adaptation governance to be most effective, it must engage a blend of both principles in the adaptation process - protect the most vulnerable and ensure an adaptation strategy for all members of the society. See N Brooks and others "Tracking adaptation and measuring development" op cit note 22, p. 11.

85 G. Ziervogel and S Parnell (note 1), 70.

86 W. N. Adger, I. Lorenzoni and K. L. O’Brien, "Adaptation now" (note 12), 9.

87 Transforming our world, (note 6).

88 K. Lofts et al, Feature- Brief on Sustainable Development Goal 13 on taking action on climate change and its Impacts: Contributions of International Law, Policy and Governance, McGill 13(1) (2017) J Sust. Dev. L, 183, 184. 
Given that adaptation to climate change impacts needs to involve anticipatory processes, ${ }^{89}$ the effectiveness of such a process would depend on its ability to aid the continued functionality of social, cultural, economic and developmental activities within communities affected by or likely to be affected by climate change. ${ }^{90}$ This points to the fact that adaptation to climate change cannot be isolated from the process of sustainable development. ${ }^{91}$ The UNFCCC encourages state parties to address challenges of climate change through sustainable development. ${ }^{92}$ Where adaptation to climate change involves deliberate actions to aid the continued functioning of the society and its various structures, the underlying causes of vulnerability are addressed. ${ }^{93}$ This indicates a synergy between the process of adaptation to climate change and sustainable development, more so if adaptation is considered as a developmental challenge, rather than an environmental concern. ${ }^{94}$

In line with the principles of sustainable development, Schipper notes that adaptation to climate change requires human systems to be able to overcome factors that cause vulnerability to climate change. Such factors include poor access to resources necessary for well-being and continued existence based on gender, age, belief system, the state of the environment in which people live and the viability of livelihoods in existing economic systems. ${ }^{95}$ Stern also emphasizes this point arguing that a good adaptation policy based on sustainable development should enable individuals to have continued sources of livelihood through diversification despite climate change impacts. ${ }^{96}$ Schipper further notes that adaptation and

89 E. L. Schipper, "Climate change adaptation and development", (note 10), 5.

90 Stern Review (note 37),430-2, the Review highlights the important role the government should play in ensuring adaptation to climate change as a way of maintaining the campaign and actions on sustainable development.

91 Stern Review (note 35), Executive Summary, 430.

92 UNFCCC, Art 3, principles 1, 4 and 5; also Goals 2, 11 and 13 of the 2030 Agenda for Sustainable Development highlight the need for sustainable development to be used as a tool to fight the challenges of climate change adaptation, especially in developing countries.

93 There is no way the impacts of climate change can be isolated from pre-existing developmental issues within individual communities. Bulkeley argues that vulnerability to climate change "cannot be divorced from existing economic and environmental challenges facing cities", H Bulkeley and R Tuts (note 14), 652.

94 E. L. F. Schipper, "Climate change adaptation and development" (note 10), 6.

95 Ibid.

96 Stern Review (note 37), 432. 
sustainability are complementary, and adaptation must entail climateproof development practices that culminate in economic and environmental sustainability. ${ }^{97}$ Thus, successful adaptation would require aligning both agendas to combat climate change impacts. ${ }^{98}$

While the government at the grassroots level might be able to meet some adaptation needs, it will be constrained in its ability to fulfil other adaptation obligations as a result of limited resources and constitutional powers. ${ }^{99}$ It is necessary, therefore, for an "all round" government involvement to achieve effectiveness in financing, regulation and implementation of adaptation policies across sectors to achieve minimum standards of liveability and sustainability. ${ }^{100}$ Cole $^{101}$ reiterates this point by stating the need for economic empowerment to adapt to the impacts of climate change properly. The UNFCCC also highlights both the economic and developmental dimensions of adaptation, especially in developing countries. ${ }^{102}$

Sustainable development is also essential in the adaptation process regarding government responsibility to safeguard public goods and the interests of the generality of people in the public sphere. The process of adaptation, however, does not exclude individuals or private stakeholders; rather the government must provide knowledge, information and general guidelines to aid autonomous adaptation within the society. ${ }^{103}$ The obligation of adaptation is a continuous working process which includes all members and stakeholders within the society to limit impacts such as monetary loss, loss of life, loss of biodiversity, distribution and equity, and the quality of life. ${ }^{104}$ Adaptation must also be geared towards reducing economic vulnerability by making information available and encouraging public participation in the adaptation process. The implication, therefore, is that nations must have well-rounded and effective adaptation plans and programmes built around government, private sector and individual actions.

97 E. L. F. Schipper, "Climate change adaptation and development" (note 10), 6-7.

98 I. R. Feldman and J. H. Kahan, "Preparing for the day after tomorrow: Frameworks for climate change adaptation" (2007) 8 Sustainable Dev. L. \& Policy 61, 62.

99 H. Bulkeley, "Cities and the governing of climate change" (note 32) 238-39, also H. Bulkeley and R. Tuts (note 14), 657.

100 Stern Review (note 37), 347.

101 D. H. Cole "Climate change adaptation and development" (2007) 26(1) UCLA Journal of Environmental Law 6.

102 UNFCCC, Art 2 and 3 (e).

103 Stern Review (note 37), 437.

104 W. N. Adger, I Lorenzoni and K. L. O’Brien, "Adaptation now" (note 12), 10. 


\subsection{Adaptation Programme and Process in Nigeria and South Africa}

Until 2010, no separate efforts were made or planned for adaptation to climate change in Nigeria. The goal was to build adaptive capacity by actualizing the Millennium Development Goals (MDGs), as well as the Sustainable Development Goals, ${ }^{105}$ and existing policies on the environment such as policies on reduction of desertification and droughts, erosion and flooding, availability of water and others. ${ }^{106}$ This was the case even though Nigeria was ranked among the ten most vulnerable countries in the world owing to the adverse effects of climate change, ${ }^{107}$ vulnerabilities in coastal areas, agriculture, urban and physical infrastructure, transportation among others. ${ }^{108}$ Sustainable development plays a significant role in adaptation to climate change, and Nigeria projects that by the year 2020 the actualization of set sustainable development goals would have aided adaptation to climate change. ${ }^{109}$ However, the level of social and geographical vulnerability in the country show that it is unlikely that this goal will be met. There remains a high level of poverty, lack of access to basic infrastructure which point to the fact that the SDGs have not been achieved. In the same vein, inability to attain the SDGs points to the continued existence of social and geographical vulnerabilities which would otherwise have been alleviated by the attainment of the SDGs.

Response to climate change in South Africa as captured in the National Climate Change Response White Paper is based on the principles of equity, special needs and circumstances, uplifting the poor and vulnerable, inter- and intergenerational sustainability (continuity) and sustainable development. ${ }^{110}$ The response to climate change impact is

105 This is as contained in the National Adaptation Strategy and Plan of Action for Climate Change Nigeria (NASPA-CCN) and Nigeria's Intended Nationally Determined Contribution available at <http://www4.unfccc.int/submissions/ INDC/Published\%20Documents/Nigeria/1/Approved $\% 20$ Nigeria's $\%$ 20INDC_271115.pdf $>$, 6 accessed 01/03/2020.

106 National Environmental, Economic and Development Study (Needs) For Climate Change in Nigeria available at <https://unfccc.int/files/adaptation/ application/pdf/nigerianeeds.pdf pp 9-12> accessed 01/03/2020.

107 Ibid.,19.

108 Ibid., 21-26.

109 Nigeria's Intended Nationally Determined Contribution ( note 104), 6.

110 The National Climate Change Response White Paper p 12 available at https:// www.environment.gov.za/sites/default/files/legislations/national_climate change_response_whitepaper.pdf,> 12 accessed 1/11/2019. 
aimed at building social, economic and environmental resilience as well as emergency responses, ${ }^{111}$ and to achieve the socio-economic goals of sustainable development by building capacity, especially in individuals.

\section{CONCLUSION}

This article has attempted a clarification of the term adaptation, first as it relates to the ability of natural systems to adapt to changes in the environment, as well as humanity's ability to adapt to changes in the weather and environment. It is established that humans have been able to adapt to environmental changes over decades. However, climate change poses new threats to the environment as well as to human systems. Hence, more than ever, the vulnerabilities of human systems become pronounced. While there are biophysical vulnerabilities, the primary challenge is that of social vulnerabilities, especially in developing and least developed countries. Social vulnerabilities point to the socioeconomic weaknesses of societies and their inability to cope with the impacts of climate change.

The need to build resilience and adaptive capacity and reduce all forms of vulnerabilities presents a strong argument for adaptation at all levels. Climate change impacts are place-specific, thus, the bottom-up approach presents the most effective mechanism for place-specific adaptation. This, however, does not derogate from the fact that successful adaptation would involve collective efforts from the international, regional, national down to the local level. The roles of the government and the law in the adaptation process were discussed, and it was highlighted that this involvement is necessary for coordinated and viable efforts towards climate change adaptation. The role of the land use governance is also essential because physical planning, as an aspect of land administration, and the law are tools for social engineering and cohesion, and climate change has and will continue involving a high level of social impacts; hence the need to promote adaptation using the law and planning systems.

At the international level, efforts have been made by the United Nations through its specialized organs to liaise and cooperate with States to aid the adaptation process. South Africa's response strategy lays out

111 The National Climate Change Green Paper 2010 (GN published in GG 25 of November 2010). 
the intended adaptation process, highlighting how the process will unfold. While not giving specific timelines and strategies, it states that the proposed responses are to be integrated into specific sectors. Based on Nigeria's climate change policies and strategies, it is argued that the country has done far less on adapting to climate change, the preoccupation being to meet the Millennium Development Goals and promote sustainable development. Both countries still have much work to do in addressing vulnerabilities, especially regarding implementing the adaptation policies on social vulnerabilities and building resilience among particularly vulnerable groups and communities.

Adaptation to climate change, as has been highlighted in this article, involves an interplay of multi-level governance, law, sustainable development, land use and management as well as other political, economic and social factors. The research, however, concentrated on the interplay between law, land use and sustainable development and adaptation to climate change. 